\title{
Post embolization complications in a case of uterine artery pseudoaneurysm
}

\author{
Rajgopal M. ${ }^{1}$, Gayam S. ${ }^{2}$, Asma T. ${ }^{3}$, Neelima ${ }^{4}$, Geeta R. ${ }^{5}$, Ahmed S. ${ }^{6}$ \\ ${ }^{1}$ Meera Rajgopal, MD MRCOG, ${ }^{2}$ Susheela Gayam, DGO DNB, ${ }^{3}$ Asma Tabasum, DGO, ${ }^{4}$ Neelima, MS (OBG), ${ }^{5}$ Geeta \\ Rani, DNB (OBG), ${ }^{6}$ Saba Ahmed, DNB (OBG), all authors are affiliated with Department of Obstetrics and \\ Gynaecology, Vijay Marie Hospital, Hyderabad, Telangana, India.
}

Corresponding Author: Asma Tabasum, Department of Obstetrics and Gynecology, Vijay Marie Hospital, Hyderabad, Telangana, India. E-mail: sushgayam@yahoo.com

\begin{abstract}
Uterine artery pseudoaneurysm is a rare cause of secondary postpartum hemorrhage; it is potentially life-threatening and can occur after caesarean section (c-section) or a hysterectomy. A 30-year-old woman who developed secondary postpartum hemorrhage 7 weeks after c-section was diagnosed to have pseudoaneurysm of left uterine artery. Embolization of the pseudoaneurysm was done with gel foam. But two days later patient developed pseudoaneurysm of right femoral artery treated by vein graft and infective endocarditis treated by medical management.
\end{abstract}

Keywords: Pseudoaneurysm, Secondary postpartum hemorrhage, angiography, Uterine artery embolization, infective endocarditis.

\section{Introduction}

Uterine artery pseudoaneurysm is a rare but potentially life threatening complication in uterine surgery, especially in cesarean section. This is also an uncommon cause of secondary post partum hemorrhage following cesarean section, vaginal delivery or dilation and curettage. Typically, the lesions are discovered because the patients have symptoms related to delayed rupture of the pseudoaneurysm, causing hemorrhage [1]. A pseudoaneurysm may be asymptomatic, may thrombose, or may lead to distal painful embolization.

Uterine artery pseudoaneurysm is an extra-luminal collection of blood with turbulent flow that communicates with the parent vessel through a defect in the arterial wall. After hematoma formation, there is central liquefaction that leaves a cavity with turbulent blood flow, as a result of persistent communication between the parent artery and the hematoma. The absence of a 3-layer arterial wall lining the pseudoaneurysm differentiates it from a true aneurysm, which is less common than a pseudoaneurysm [2].

The risk of rupture is proportional to the size and intramural pressure. Diagnosis is usually based on both Doppler sonography and arteriography [3]. Transcatheter uterine artery embolization (UAE) has emerged as a highly effective technique for controlling obstetric and gynecologic hemorrhage, including that from pseudoaneurysms [3].

\section{Case Report}

A 30 year old primiparous woman who underwent emergency LSCS 48 days ago was brought to hospital, in a state of shock. She presented with sudden onset of heavy bleeding per vagina of 40 minute duration. On examination patient was cold, clammy with feeble pulse and blood pressure $80 / 50 \mathrm{~mm} \mathrm{Hg}$. She was resuscitated immediately and bleeding was stopped with a Foleys balloon tamponade. Her coagulation profile was normal. Ultrasound doppler showed left uterine artery aneurysm with organized blood clot. MRI showed pseudo aneurysm of left uterine artery (picture1). Patient was referred to interventional radiologist for embolisation. Both uterine arteries were embolised with gel foam.

Manuscript received: $10^{\text {th }}$ June 2019

Reviewed: $20^{\text {th }}$ June 2019

Author Corrected: $26^{\text {th }}$ June 2019

Accepted for Publication: $30^{\text {th }}$ June 2019 


\section{Case Report}

Two days following procedure patient developed high grade fever with pain and swelling in right leg. Review scan showed small pseudoaneurysm in right common femoral artery with digital embolism. Two openings in the common femoral artery, suggestive of mycotic aneurysm related to aortic valve infective endocarditis. Infective endocarditis was treated by Medical management. Right common femoral artery replacement with vein graft was done. Patient recovered completely.

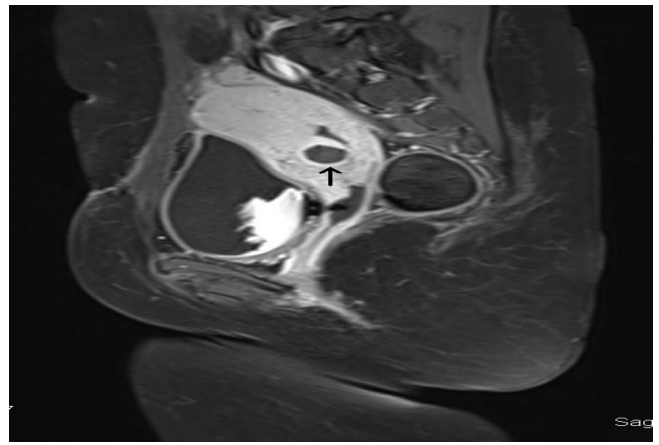

Figure 1: MRI pelvis, arrow pointing uterine artery pseudoaneurysm

\section{Discussion}

Uterine artery pseudoaneurysm is a rare but serious complication of pelvic surgery (although there are some cases reported following normal delivery), which can manifest as a severe bleeding in the postoperative period [4]. Prevalence is difficult to determine due to its rarity. A prevalence of 2-3 / 1000 deliveries has been cited when asymptomatic patients are included [5].

Pseudo aneurysms have been formed after vaginal deliveries and caesarean deliveries, as well as dilation and curettage, myomectomies, and cervical conization [5]. Pseudoaneurysms differ from a true aneurysm because they have only a single layer of connective tissue, rather than a three-layer wall. Due to high pressure in the artery, blood can extravasate through the connective tissue, leading to vaginal bleeding [5]. The diagnostic modality of choice is trans vaginal ultrasound with colourdoppler. Uterine artery pseudoaneurysms typically present as hypoechoic mass with a "ying-yang" pattern on Doppler [2].

Uterine artery pseudoaneurysms can also be seen on magnetic resonance imaging and computed tomography with contrast [5]. For hemodynamically stable patients the treatment of choice is interventional radiology embolization of the uterine artery [5].

Selective embolization of both uterine arteries is recommended [6]. Embolization should be performed using gelatin sponge pledgets. Control of hemorrhage is obtained in 85 to $100 \%$ of cases [6]. Interventional radiology embolization is the preferred method because it is well tolerated by the patient, less invasive, allows for shorter hospitalization and preserves fertility, in contrast to hysterectomy [5]. For hemodynamically unstable patients, intraoperative ligation of the uterine vessels and hysterectomy are the options. Dilatation and curettage should be avoided in these patients because it can disrupt the pseudoaneurysm, leading to heavier bleeding. (This is important to prevent because delayed postpartum haemorrage is often attributed to retained products of conception).

Prior to proceeding with curettage, uterine artery pseudoaneurysm should be ruled out [5]. Major complications related to embolization are reported in $5 \%$ of cases. The presence of coagulation disorders is not a contraindication to embolization [6]. Uterine artery pseudoaneurysm is a rare cause of delayed postpartum hemorrhage. Early diagnosis and endovascular management are effective in treating this condition $[7,8]$.

\section{Conclusion}

Uterine artery pseudoaneurysm is a rare but serious complication. Many reported cases were treated without any complications. There are only a couple of case reports showing complication following uterine artery embolization.

This emphasizes the need to counsel the patient regarding complications. Timely diagnosis and intervention played a vital role in complete recovery from this condition which was "A near miss" in this patient.

Funding: Nil, Conflict of interest: Nil Permission from IRB: Yes 


\section{Case Report}

\section{References}

1. Langer JE, Cope C. Ultrasonographic diagnosis of uterine artery pseudoaneurysm after hysterectomy. J Ultrasound Med. 1999;18(10):711-4. DOI: https://doi. org/10. 7863/jum.1999.18.10.711

2. Kwon JH, Kim GS. Obstetric iatrogenic arterial injuries of the uterus: diagnosis with US and treatment with transcatheter arterial embolization. Radiograp. 2002; 22(1): 35-46. DOI:10.1148/radiographics.22.1. g02ja 0735

3. Hidar S, Bibi M, Atallah R, Essakly K, Bouzakoura C, Hidar M. [Pseudoaneurysm of the uterine artery: apropos of 1 case]. J GynecolObstet Biol Reprod (Paris). 2000; 29 (6):621-4. DOI:10.1097/00004583200008000-00020

4. Pérez-Ezquerra BR, Carazo-Hernández B, ArribasMarco T, Guardia-Dodorico L. [Pseudoaneurysm of the uterine artery after cesarean delivery]. GinecolObstet Mex. 2013;81(3):166-70.
5. Parr K, Hadimohd A, Browning A, Moss J. Diagnosing and treating postpartum uterine artery pseudoaneurysm. InBaylor University Medical Center Proceedings. Taylor \& Francis. 2018;31(1):56-58). DOI: $10.1080 / 08998280.2017 .1400301$

6. Pelage JP, Fohlen A, Le Pennec V. [Role of arterial embolization in the management of postpartum hemorrhage]. J GynecolObstet Biol Reprod (Paris). 2014; 43 (10):1063-82. DOI: 10.1016/j.jgyn.2014.10. 002. Epub 2014 Nov 7.

7. Vilos GA, Urian R, Chang P, Kozak R. Femoral artery puncture site pseudoaneurysm formation following uterine artery embolization for symptomatic fibroids: a case report. J ObstetGynaecol Can. 2009; 31(3):263-266. DOI: 10.1016/S1701-2163(16)34125-1.

8. Wu CQ, Nayeemuddin M, Rattray D. Uterine artery pseudoaneurysm with an anastomotic feeding vessel requiring repeat embolisation. BMJ Case Rep. 2018. pii: bcr-2018-224656. DOI: 10.1136/bcr-2018-224656.

\section{How to cite this article?}

Rajgopal M, Gayam S, Asma T, Neelima, Geeta R, Ahmed S. Post embolization complications in a case of uterine artery pseudoaneurysm. Obs Rev: J obstet Gynecol 2019;5(2):125-127.doi:10.17511/joog.2019.i02.07. 